\title{
Environmental risk assessment of the most commonly transported chemicals: case study of Finnish coastal areas
}

\author{
Jani Häkkinen • Vuokko Malk • Antti Posti • \\ Olli-Pekka Penttinen • Riikka Mäkelä • Anna Kiiski
}

Received: 5 July 2012 /Accepted: 5 April 2013 / Published online: 18 April 2013 (C) World Maritime University 2013

\begin{abstract}
The environmental hazard potential of a total of 15 chemicals that are transported through the Finnish coastal areas was assessed in this paper using a scoring method developed for accidents. The study indicates that the chemicals most commonly transported/handled in Finnish ports are methanol, sodium hydroxide solution, acids, pentanes, phenol, xylenes, methyl tert-butyl ether, ethanol and ethanol solutions. For the evaluation of the environmental hazardousness of various chemicals, a priority list of chemicals that are the most commonly transported regionally in marine environments was compiled for this study. The method used has many similarities to other commonly used scoring systems, but this study gave more weight to specific characteristics of an accidental release, water biota and impact on the environment. Nonylphenol, ammonia and sulphuric acid ranked as the most hazardous substances on the list. The results of the study can be used by rescue and environmental authorities and enterprises to improve preparedness for accidents and to mitigate the effects of accidental spills.
\end{abstract}

Keywords Transportation of chemicals · Environmental risk management · Scoring method $\cdot$ Transport-related accidents $\cdot$ Logistics

\footnotetext{
J. Häkkinen $(\bowtie) \cdot$ A. Posti

Centre for Maritime Studies, University of Turku, Heikinkatu 7,

48100 Kotka, Finland

e-mail: jani.hakkinen@utu.fi

V. Malk $\cdot$ R. Mäkelä $\cdot$ A. Kiiski

Palmenia Centre for Continuing Education, University of Helsinki, Metsontie 41 A, 48220 Kotka, Finland

O.-P. Penttinen

Department of Environmental Sciences, University of Helsinki,

Niemenkatu 73, 15140 Lahti, Finland
} 


\section{Introduction}

The Baltic Sea is one of the busiest sea routes in the world, and it is highly sensitive to the environmental impacts of a possible chemical accident. At present, a quarter of the vessels sailing in the Baltic Sea are oil tankers or tankers carrying chemicals (HELCOM 2009). Navigation in the Baltic Sea is challenging due to the sea area's relative shallowness, narrow navigation routes and ice cover in the winter. This is especially true for Finland. Recently, both the number and the volume of chemicals transported in the Baltic Sea have increased significantly (HELCOM 2009), concomitantly raising the spill/ship-collision risk (Kujala et al. 2009). The results of previous studies (e.g. EMSA 2010; Hänninen and Rytkönen 2006; Mullai 2007; Suominen and Suhonen 2007) indicate that both the risks and incidents of spills are less well defined for chemical transportation than for oil transportation. According to HELCOM (2012), there have been 1,400 accidents, and 1,520 vessels in total have been involved in the accidents that occurred in the Baltic Sea during the years 19892010. One in seven of the accidents involved a tanker. Based on the HELCOM's accident statistics, 210 tankers including crude oil tankers, chemical tankers, oil/chemical product tankers, gas carriers and other types of vessels carrying liquid bulk cargoes were involved in the accidents that occurred in the Baltic Sea during the years 1989-2010. During this period, 28 of all tanker accidents in the Baltic Sea led to some sort of pollution, and in one pollution case only, the spilled substance was a chemical. Generally speaking, the chemical tanker accidents are rare, even though there is always the possibility that such incident may happen. Further, due to the wide range of chemicals transported, it is necessary to identify the potency of different chemicals to cause environmental damage.

International liquid bulk cargoes handled in Baltic Sea ports in 2010 consisted of approximately 290 million tonnes of oil and oil products, 11 million tonnes of liquid chemicals, and 4 million tonnes of other liquid bulk (Holma et al. 2011; Posti and Häkkinen 2012). The share of Finnish ports in all liquid bulk chemicals transported is approximately 3.5 million tonnes annually (Holma et al. 2011; Häkkinen 2009; Posti and Häkkinen 2012). The chemicals most commonly transported in the entire Baltic Sea area are methanol, sodium hydroxide solution, ammonia, sulphuric and phosphoric acid, pentanes, xylenes, methyl tert-butyl ether (MTBE), ethanol and ethanol solutions. At least one hundred to several hundred thousand tonnes, or even a million tonnes, of all these chemicals are transported annually, but since chemical-specific data from all Baltic Sea countries are not available, the exact volumes could not be calculated. Besides these chemicals, high volumes of other chemicals are also transported (e.g. ethylene, propane and butane), and large amounts of fertilisers and vegetable oils are handled in the Baltic Sea ports (Hänninen and Rytkönen 2006; Posti and Häkkinen 2012).

The marine pollution hazards of thousands of chemicals have been evaluated by such bodies as the Evaluation of Hazardous Substances Working Group, producing a GESAMP Hazard Profile which indexes each substance according to its bioaccumulation, bio-degradation, acute toxicity, chronic toxicity, long-term health effects, and effects on marine wildlife and on benthic habitats. Based on the 
GESAMP evaluation, the IMO has set up four different hazard categories: X (major hazard), Y (hazard), Z (minor hazard) and OS, i.e. other substances (no hazard) (IMO 2007). More than $80 \%$ of all the chemicals transported in the Baltic Sea are classified as belonging to the $\mathrm{Y}$ category (Häkkinen 2009). This GESAMP categorization is very comprehensive, but chemicals with very different toxicity mechanisms, environmental fate and other physico-chemical properties may end up in the same MARPOL category. The GESAMP categorization is neither a prioritisation method nor can be used to evaluate and rank the hazard potentials of chemicals.

A substance with a relatively low toxicity that is used or transported frequently can pose a risk to human health and the environment. On the other hand, the environmental impact of a more hazardous chemical may be more severe, even if the probability of an accident occurring is very low. Different risk-based scoring methods can be used to compare and categorise chemicals to support, e.g. legislation when prioritising hazardous chemicals. In many scoring systems, chemical exposure is, for example, assessed based on the total consumption, the amount required in a specific industrial process or the history of accidents involving the substance (Adu et al. 2008; Singh et al. 2011). Several indices that combine the chemical hazard and the extent of exposure into a single numerical indicator to rank the risk posed by a chemical have been developed. Davis et al. (1994) introduced 51 chemical ranking systems, and recently, many excellent reviews have been published (e.g. Adu et al. 2008; Singh et al. 2011). Different scoring systems have different weightings and can be grouped into categories based on at least three aspects related to the environment, health and safety. In this study, environmental impacts were emphasised, especially impacts on the biota of the water column. In case of a shipping accident, three major physicochemical characteristics, including density, water solubility and vapour pressure, determine the fate of the chemical (French McKay et al. 2006). Further, the hazardousness of chemicals for the water biota could be determined by their ecotoxicity, persistency and bioavailability.

The objective of this study was to evaluate the environmental risk of the most commonly transported chemicals in case of a shipping accident in the Finnish coastal areas. As a result of the risk assessment, a chemical priority list was compiled using a scoring method. The aim of the priority list is to help the authorities and other stakeholders to pay attention to the most hazardous chemicals and, further, use this information to minimise the risk of chemical accidents. Another aim was to introduce a scoring method in which the number of parameters is optimised to assess the environmental hazard potential of chemicals in other sea areas.

\section{Methodology}

The study was conducted in two stages. In the first stage of the study, the volumes of each chemical handled in Finnish ports were examined to establish which chemicals are handled the most commonly in Finland. Based on this transport data, chemicals included in the environmental risk assessment were chosen. The information on chemicals handled in Finnish ports was obtained directly from a nationwide vessel 
traffic system called 'PortNet', in which each and every ship calling at a Finnish port is obliged to provide information regarding its schedule, route, cargo, hazardous cargo and maritime fees. The volumes of chemicals (total of exports and imports) handled in Finnish ports in 2 years (2008 and 2010) were collected on the basis of dangerous goods declarations obtained from the PortNet information system. Year 2009 was excluded from the review since the cargo volumes in Finnish ports in that year were significantly lower than in 2008 and 2010, mainly due to the global economic depression at that time (Holma et al. 2011; Särkijärvi et al. 2009; Särkijärvi et al. 2010). The PortNet system showed that the volumes and number of chemicals in selected years were also much higher than those in 2009. Therefore, year 2009 was considered to be too incomparable with the years 2008 and 2010, and including the year 2009 would not give any additional value to our risk assessment study. While the study focused on liquid bulk chemicals, gases transported as liquefied bulk were also taken into account. Chemicals in a packaged form were excluded from the study, as their transportation volumes are much lower than those of bulk chemicals, and the volumes per voyage are also considerably low. For example, $97 \%$ of hazardous cargoes handled in Finnish ports are transported as bulk, and only $3 \%$ as packaged cargo (Häkkinen 2009).

In the second stage of the study, the environmental hazardousness of a total of 15 chemicals chosen on the basis of the PortNet analysis was evaluated. Of these, ten chemicals are transported in very high volumes through the Finnish ports (Table 2), and the remainder have a significant environmental hazard potential. The risk assessment was carried out using a scoring method originally developed to estimate the environmental risk in chemical accidents on land (Häkkinen et al. 2010). For this reason, some parameters used in this study naturally are different. In soil studies, the density-toviscosity ratio has an influence on the chemical mobility in soil, but this value has no role in an aquatic environment. The above-mentioned parameter was replaced by density in this study. In addition, volatility threshold values for a marine environment were determined according to French McKay et al. (2006), while threshold values for land accident scenarios are based on Nikunen and Leinonen (2002).

The method used has many similarities to other commonly used scoring systems, but this study gave more weight to specific characteristics of an accidental release, water biota and impact on the environment. The chemicals were assessed based on nine parameters which were considered the main factors affecting their environmental fate or mobility, ecotoxicology and probability of being involved in an accident (Table 1). For each parameter, the chemicals were assessed on a scale of 1 to 3 , the most hazardous chemicals receiving 3 points. The total number of points was added up, and a priority list for hazardous chemicals was formed. The parameter values for chemicals were obtained from tens of scientific articles, from EU documents, Canada and United States Environmental Agency risk assessment reports, field literature and databases (the original values are presented in more detailed in Häkkinen et al. 2010). Data gaps were filled in by means of a modelling exercise using the US EPA's EPISuite program. EPISuite has been used worldwide in several scoring methods to fill in data gaps (e.g. Juraske et al. 2007). The environmental fate and ecotoxicology values used in the scoring and their references have been compiled in Häkkinen et al. (2010) for most chemicals and are not presented in this paper. For NExBTL (renewable biodiesel, a product name), the 


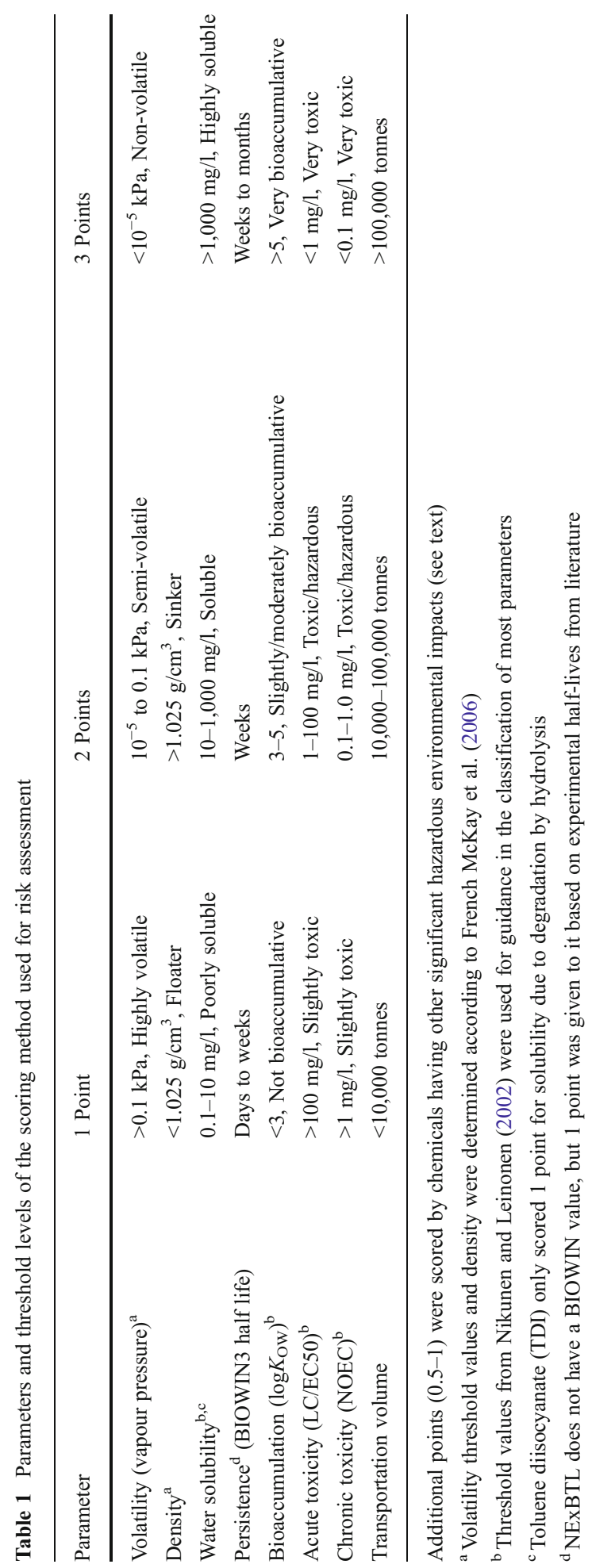


parameter values were obtained from the ECHA (2012) database and California Environmental Protection Agency (2010). For a more detailed description of the parameters used, please refer to the following section.

\subsection{Parameters assessed}

Three major physico-chemical characteristics, i.e. density, water solubility and vapour pressure, determine the fate of a chemical in case of a shipping accident (French McKay et al. 2006). Water solubility is the most important parameter when assessing the chemical's hazard potential for water environment and biota. In the scoring method, the most water soluble chemicals were considered most likely to enter the water column and to spread over wider areas, and therefore to be the most hazardous. Density determines a chemical's buoyancy relative to water. The chemical quickly disperses if its water solubility is high, but floats or sinks depending on its density if its solubility is low. Since ecotoxicological effect on water column biota was weighted in this study, chemicals that sink (density $>1.025 \mathrm{~g} / \mathrm{cm}^{3}$ ) scored 2 points, while floaters scored 1 point (density $<1.025 \mathrm{~g} / \mathrm{cm}^{3}$ ) (GESAMP 2002; French McKay et al. 2006). Many risk scenarios take the opposite view, especially when public health is a priority. The volatility of the chemicals was assessed based on vapour pressure. The highest points were scored by compounds with poor volatility (low vapour pressure), since a larger portion of these chemicals stay in the water column (Table 1) and, therefore, the environmental impact of non-volatile chemicals is higher.

The biodegradability of chemicals was defined using BIOWIN3 values modelled using the US EPA's EPISuite program. The modelled values were used to harmonise half-life values. The bioaccumulation of chemicals was estimated using the octanolwater partition coefficient $\left(K_{\mathrm{OW}}\right)$. The greater the $K_{\mathrm{OW}}$, the more hydrophobic and bioaccumulative the chemical is. The majority of the chemicals studied are not bioaccumulative $\left(\log K_{\mathrm{OW}}<3\right)$ and can be considered relatively non-hazardous to the environment. The acute and chronic toxicity of chemicals were examined for three trophic levels (algae, Daphnia magna - water flea and fish) based on the lowest acute LC/EC50 (lethal/effective concentration, where $50 \%$ of organisms are affected) and chronic NOEC (no observed effect concentration) values defined. Acute and chronic toxicity were examined individually by calculating the averages of points scored for toxicity for the three trophic levels.

Based on studies that include all transport modes, the greatest accident probability is posed by the most commonly transported chemicals, i.e. liquid fuels (Mullai and Larsson 2008, Häkkinen et al. 2010). The volumes transported by sea obtained from the PortNet system were thus used to indicate the probability of chemical exposure. In addition, some chemicals scored 0.5-1 additional points if they had significant hazardous environmental impacts, for instance based on their carcinogenic potential or endocrine effects. Simple weight-of-evidence approach was applied by focusing on the chemicals' mechanisms of toxicity (e.g. carcinogenicity, endocrine disruption or other additional hazardous property as criteria). Therefore three scored chemicals received 0.5 carcinogenicity point, some others $0.5 \mathrm{HP}$ points, but ammonia and nonylphenol got 1 additional point each by having several hazardous properties in terms of transport accidents and especially impact to the environment. 
Table 2 Volumes of chemicals handled in Finnish ports (exports + imports) in 2008 and 2010

\begin{tabular}{|c|c|c|c|}
\hline \multicolumn{2}{|l|}{2008} & \multicolumn{2}{|l|}{2010} \\
\hline Chemical & Volume (tonnes) & Chemical & Volume (tonnes) \\
\hline Methanol & 866,323 & Methanol & 746,141 \\
\hline Sodium hydroxide solution & 359,424 & Sodium hydroxide solution & 380,331 \\
\hline Xylenes & 206,558 & Pentanes & 315,978 \\
\hline Ethanol and ethanol solutions & 149,535 & Xylenes & 161,894 \\
\hline Phosphoric acid & 133,147 & Methyl tert-butyl ether (MTBE) & 159,660 \\
\hline Pentanes & 124,548 & $\begin{array}{l}\text { Aromatic free solvents } \\
\text { (e.g. white spirit and NESSOL) }\end{array}$ & 155,363 \\
\hline Methyl tert-butyl ether (MTBE) & 119,539 & Ethanol and ethanol solutions & 122,018 \\
\hline Phenol + acetone & 119,065 & Parafines & 111,079 \\
\hline $\begin{array}{l}\text { Aromatic free solvents } \\
\text { (e.g. white spirit and NESSOL) }\end{array}$ & 111,479 & Phosphoric acid & 91,797 \\
\hline Propane & 107,260 & Phenol & 87,359 \\
\hline Ethyl tert-butyl ether (ETBE) & 73,646 & Propane & 84,027 \\
\hline Phenol & 73,040 & Acetone & 73,815 \\
\hline Ammonia & 72,088 & NExBTL & 73,298 \\
\hline Propylene & 66,818 & Phenol + acetone & 72,427 \\
\hline Sulphuric acid & 62,822 & Styrene & 71,934 \\
\hline Butadiene & 60,340 & Benzene & 69,240 \\
\hline Styrene & 59,423 & Formic acid & 68,427 \\
\hline Hexafluorosilicic acid & 57,896 & Butanoles & 67,890 \\
\hline Benzene & 56,841 & Hexafluorosilicic acid & 56,006 \\
\hline Tert-amyl ethyl ether (TAEE) & 54,239 & Ammonia & 51,632 \\
\hline Total of other chemicals & 625,837 & Total of other chemicals & 435,876 \\
\hline Total & $3,559,868$ & Total & $3,456,192$ \\
\hline
\end{tabular}

Compiled from the PortNet system in 2012

\section{Results}

\subsection{Liquid bulk chemicals handled in Finnish ports}

According to the PortNet system, Finnish ports handled approximately 3.5 million tonnes of liquid bulk chemicals consisting of some 60 different chemicals in 2010. Eight of these chemicals were handled in volumes exceeding 100,000 tonnes, and 37 chemicals in volumes exceeding 10,000 tonnes. The chemicals handled in the greatest volumes were methanol, sodium hydroxide solution and pentanes (Table 2). Of all liquid bulk chemicals handled in Finnish ports in 2010, the exports of liquid bulk chemicals accounted for about $73 \%$, and the imports of liquid bulk chemicals for about $27 \%$. The liquid bulk chemicals exported in the greatest quantities were methanol, pentanes and xylenes, while the most commonly transported liquid bulk chemicals were sodium hydroxide solution, ethanol, ethanol solutions and propane. Compared to 2008, the total volume of liquid bulk chemicals handled in Finnish ports 
in 2010 decreased by approximately $3 \%$. The number of different liquid bulk chemicals also decreased from 80 to 57 . However, the most commonly handled liquid bulk chemicals remained more or less the same as in 2008 in 2010, nine out of ten of the most commonly handled chemicals being the same in these years. Only the amounts of these nine chemicals varied in the years under scrutiny.

\subsection{Environmental risk assessment of chemicals using the scoring method}

In the second stage of the study, the environmental hazardousness of a total of 15 chemicals that are transported through the Finnish ports was assessed using a scoring method originally developed by Häkkinen et al. (2010), even though the method was slightly modified for the purposes of this study (for details, see the 'Methodology' section). Of these 15 chemicals chosen for assessment, 10 or 11 can be classified as chemicals with very high volume depending on the year (Table 3), and 6 of them belong to the top 10 chemicals handled in the Finnish ports. The remainder of the chemicals, namely toluene diisocyanate (TDI), 1-decene, epichlorohydrine and nonylphenol, are transported in lower volumes, and they were included in the assessment on the grounds of pre-evaluations of their environmental properties and due to the fact that they represent very different types of chemicals. In addition, a decision was made to include NExBTL in the evaluation because it represents a new renewable diesel with potentially very high transport volumes in the future.

Table 3 Chemicals and their volumes (in tonnes) chosen for the environmental risk assessment on the basis of the PortNet analysis

\begin{tabular}{lllll}
\hline 2008 & & & 2010 & \\
\cline { 1 - 2 } \cline { 5 - 5 } Chemical & Volume (tonnes) & & Chemical & Volume (tonnes) \\
\hline Methanol & 866,323 & & Methanol & 746,141 \\
Xylenes & 206,558 & & Pentanes & 315,978 \\
Ethanol and ethanol solutions & 149,535 & & Xylenes & 161,894 \\
Pentanes & 124,548 & & Methyl tert-butyl ether (MTBE) & 159,660 \\
Methyl tert-butyl ether (MTBE) & 119,539 & & Ethanol and ethanol solutions & 122,018 \\
Phenol + acetone & 119,065 & & Phenol & 87,359 \\
Phenol & 73,040 & & NExBTL & 73,298 \\
Ammonia & 72,088 & & Phenol + acetone & 72,427 \\
Sulphuric acid & 62,822 & & Styrene & 71,934 \\
Styrene & 59,423 & & Benzene & 69,240 \\
Benzene & 56,841 & & Ammonia & 51,632 \\
Nonylphenol ethoxylates & 29,160 & & Sulphuric acid & 25,172 \\
NExBTL & 12,806 & & Nonylphenol ethoxylates & 11,082 \\
Epichlorohydrin & 9,328 & Alpha olefines (e.g. 1-decene) & 3,737 \\
Alpha olefines (e.g. 1-decene) & 7,058 & Epichlorohydrin & 480 \\
Toluene diisocyanate & 23 & Toluene disocyanate & 23 \\
& & & &
\end{tabular}

Compiled from the Finnish Transport Agency figures in 2012 
The chemicals were ranked by summing up the scores for all the parameters (Table 4). The chemicals with the highest total score can be considered the ones with the greatest environmental risk. In case of a shipping accident, the greatest risk to the environment is posed by chemicals with a high solubility, which stay in the water column and are bioavailable, persistent and toxic to organisms. Most of the chemicals studied are highly water soluble, while nonylphenol, TDI, 1-decene and NExBTL are only moderately soluble in water. Based on BIOWIN3 values, benzene is the most persistent of the chemicals observed and thus presents the highest long-term risk to the environment. For the most part, the modelled values correlate well with experimental values found in the scientific literature (the original values presented in more detailed in Häkkinen et al. 2010), however excluding inorganic compounds. Of the chemicals studied, only 1-decene and nonylphenol are highly bioaccumulative. Based on their density, nonylphenol, sulphuric acid, phenol, epichlorohydrin and TDI are so-called sinkers and will enter the water column, although sulphuric acid also has a high volatility, which will affect its migration in the opposite way. The most toxic chemicals in this study were nonylphenol and ammonia, while ethanol, MTBE and NExBTL were the least toxic.

Nonylphenol scored one additional point based on its other hazardous impacts, as it is known to be an endocrine disrupter and very persistent in the environment. Benzene and epichlorohydrin are carcinogenic chemicals, and for this reason, both scored 0.5 additional points. TDI is known to be a genotoxic and possibly carcinogenic chemical that is very toxic to mammals and degrades into more persistent and toxic toluene diamine. Ammonia is a very complex chemical that can affect water $\mathrm{pH}$ and may cause eutrophication of water if spilled in large volumes. If spilled in water, it has very low toxicity values (= high toxicity) (e.g. lowest acute toxicity value for fish is $0.083 \mathrm{mg} / \mathrm{l}$ and lowest chronic value $0.07 \mathrm{mg} / \mathrm{l})$. Additionally, it also forms highly toxic gas clouds (Häkkinen et al. 2010).

Nonylphenol was determined as the most hazardous of the chemicals studied in case of a marine spill. Besides its toxicity, it is very persistent, bioaccumulative and has a moderate solubility in water. Nonylphenol is not one of the most commonly transported chemicals in the Baltic Sea, but approximately 10-30 thousand tonnes of nonylphenol ethoxylates are transported annually through Finnish coastal areas. When spilled in the environment, nonylphenol ethoxylates are transformed into more harmful nonylphenol, and this worst-case scenario was evaluated in this study. Other very hazardous substances on the priority list were sulphuric acid and phenol. The least hazardous chemicals were renewable biodiesel NExBTL and alpha olefin 1-decene, both of which bioaccumulate easily but are readily biodegradable and relatively non-toxic.

\section{Comparison with other risk assessment methods}

In a potential shipping accident, the greatest risk to the environment is posed by chemicals with high solubility, which stay in the water column, are bioavailable, persistent and toxic to organisms. Our study indicates that nonylphenol is the most toxic of the chemicals studied and the most hazardous if spilled in the sea. It is persistent, bioaccumulative and has a moderate solubility in water. Nonylphenol is actually transported in the form of nonylphenol ethoxylates, but if spilled in the 


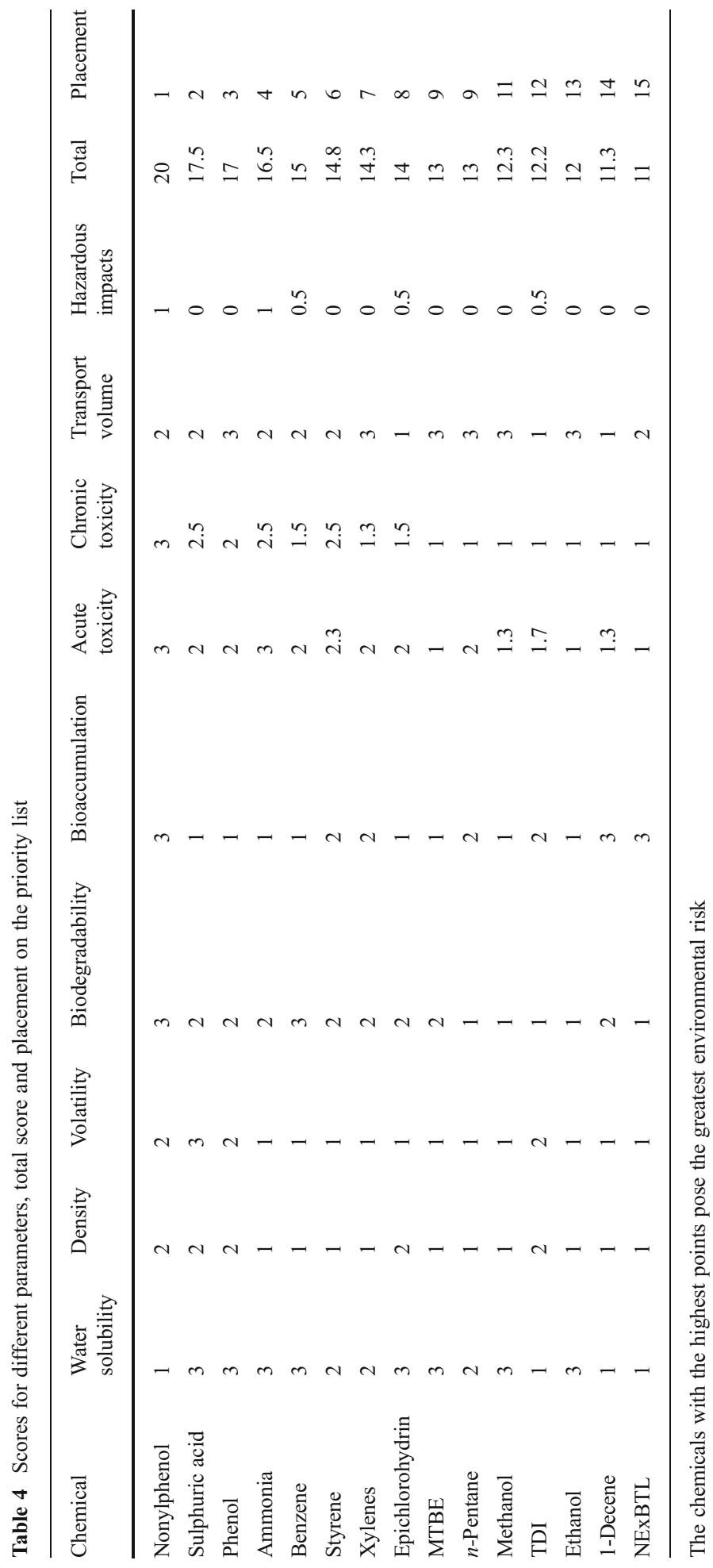


environment, it will be present as nonylphenol; and this study analysed the worst-case scenario. Other very hazardous substances were sulphuric acid and ammonia (Table 4). The Drogou et al. (2005) project identified 100 chemicals that are the most commonly transported between major European ports as part of the trade through the English Channel to the rest of the world. The assessment was based on both transport volumes and the GESAMP hazard profile. The project highlighted such chemicals as benzene, styrene, vegetable oil, xylene, methanol, sulphuric acid, phenol, vinyl acetate and acrylonitrile. It concluded that these chemicals were the ones that have a high spillage probability but that may not result in significant environmental impacts. Similarly, French McKay et al. (2006) applied a predictive modelling approach to a selected range of chemicals transported by sea in bulk and concluded that phenol and formaldehyde present the greatest risk to aquatic biota. Furthermore, Guerbet and Jouany (2002) used the SIRIS method to evaluate 90 chemicals based on the risk they pose to the aquatic environment. Only a handful of chemicals included in our study were included in the study by Guerbet and Jouany (2002). Benzene, for example, ranked 6th (high risk for the environment) and chloroform 14th, while such chemicals as xylenes came in 88th place. Harold et al. (2011) evaluated human health risks of transported chemicals based on the GESAMP ratings for toxicity and irritancy. Their evaluation gives more weight to chemicals that are floaters, form gas clouds, irritate and are toxic, such as chlorine (Harold et al. 2011). It is clear that different weightings have a certain impact on the difference in results produced by these studies. In this paper, the focus was to assess the environmental effects of the selected chemicals, with emphasis on water column biota and accident probability.

The scoring method and parameters used in this study have both similarities and differences when compared to other scoring systems. Chemicals are assessed from the point of view of their environmental hazard in systems such as ERICA (Boriani et al. 2010), CROSS (Jeong and An 2012), PestScreen (Juraske et al. 2007), EURAM (Hansen et al. 1999) and CHEMS-1 (Swanson et al. 1997). Most of these methods rely on calculating the Predicted Environmental Concentration (PEC), creating environmental models on the basis of monitoring data. In this study, however, PEC was not determined for maritime accidents, as this would require complex 3D modelling using such programs as CHEMMAP (French McKay et al. 2006), and this was beyond the scope of the study. CHEMS-1 (Swanson et al. 1997) had very similar parameters to those used in our scoring method, including toxicity values, persistence, bioaccumulation, degradation and amount of release. In their Environmental Consequence Index, Arunraj and Maiti (2009) had a different approach and focused on the environmental fate and distribution of chemicals as did Davis et al. (1994) with a different parameter set. On the other hand, the EURAM method (Hansen et al. 1999), which had separate scores for human health and the environment, had similarities to our scoring method, but risks to human health are weighted more in the EURAM method.

\section{Conclusions}

This paper discusses the most commonly handled liquid bulk chemicals in the Finnish ports and, especially, the environmental hazard potential of chemicals evaluated using a 
novel prioritizing scoring method. A user-friendly method for evaluating chemical hazardousness in the maritime environment was introduced. The method was used to evaluate the environmental hazardousness of chemicals transported through the Finnish coastal areas, but it can also be applied to other sea areas.

The chemicals most commonly transported through the Finnish ports are mainly the same as in other sea areas (AMRIE 2005). This in turn shows that the safety issues related to the maritime transport of chemicals are similar in different sea areas around the world. Naturally, the hazardousness of a chemical spill depends on the vulnerability of the environment. Compared to large oceans, the Finnish coastal areas are shallow with a low water exchange rate, and they are covered by ice for extended periods in winter. Once released in the Baltic Sea, hazardous substances may remain there for decades, accumulating in food webs until they reach toxic levels and cause harmful effects on the sensitive ecosystem. The most commonly handled chemicals in Finnish and other ports are usually basic industrial chemicals (e.g. methanol, sodium hydroxide solution, xylenes, ammonia, phosphoric acid and ethanol) that often have been overlooked in environmental assessments. Many of these chemicals have a surprisingly high environmental hazard potential. To evaluate the environmental hazardousness of different chemicals, a priority list of chemicals that are regionally the most commonly transported by sea was formed in this study. The method used has many similarities with other commonly used scoring systems. However, it gives more weight to the specific characteristics of an accidental release and the impact on the aquatic environment. Nonylphenol, ammonia and sulphuric acid were ranked as the most hazardous substances on the list.

This paper discusses the special case of Finnish coastal areas, focusing on a limited number of chemicals. In the future, all liquid bulk chemicals transported by sea should be evaluated thoroughly, weighting their effects on water biota. A similar evaluation should also be carried out for chemicals transported in packaged form. The information on chemical risks can be used by rescue and environmental authorities and enterprises to improve preparedness for accidents and to mitigate their effect in the case of an accidental spill.

Acknowledgments This article was written as part of the Chembaltic and Risk Management and Remediation of Chemical Accidents research projects. The authors would like to extend their special thanks to the European Regional Development Fund/the Finnish Funding Agency for Technology and Innovation (TEKES), Central Baltic Interreg IVA programme (2007-2013), the companies and other stakeholders supporting the research projects, and all research partners and co-workers involved in these projects. The publication reflects the authors' views. The Managing Author cannot be held liable for the information published.

\section{References}

Adu IK, Sugiyama H, Fischer U, Hungerbuhler K (2008) Comparison of methods for assessing environmental, health and safety (EHS) hazards in early phases of chemical process design. Proc Saf Environ Protect 86:77-93

AMRIE (2005) Monitoring of the flow of chemicals transported by sea in bulk and in package form. HASREP (Response to harmful substances spilled at sea) project. Report on task 1. http://ec.europa.eu/ echo/civil_protection/civil/marin/reports_publications/hasrep.zip. Accessed 23 Mar 2012 
Arunraj N, Maiti J (2009) Development of environmental consequence index (ECI) using fuzzy composite programming. J Hazard Mater 162(1):29-43

Boriani E, Mariani A, Baderna D, Moretti C, Lodi M, Benfenati E (2010) ERICA: a multiparametric toxicological risk index for the assessment of environmental healthiness. Environ Int 36:665-674

California Environmental Protection Agency (2010) Renewable diesel multimedia evaluation. Draft FINAL Tier I Report. The University of California, Davis and The University of California, Berkeley

Davis GA, Swanson MB, Jones SL (1994) Comparative evaluation of chemical ranking and scoring methodologies. Center for Clean Products and Clean Technologies, University of Tennessee, Knoxville

Drogou B, Laruelle F, Le Floch S (2005) Response to harmful substances spilled at sea. HASREP. Task 2: Risk assessment methodology for the transport of hazardous and harmful substances in the European Union marine waters. R.05.75.C. Brest, Cedre

ECHA (2012) Information on chemicals. http://echa.europa.eu/web/guest/information-on-chemicals. Accessed 1 Feb 2012

EMSA (2010) Maritime accident review 2009. http://www.emsa.europa.eu/download/308/216/23.html. Accessed 3 Feb 2012

French McKay DP, Whittier N, Ward M, Santos C (2006) Spill hazard evaluation for chemicals shipped in bulk using modelling. Environ Modell Softw 21:156-159

GESAMP (2002) The revised GESAMP hazard evaluation procedure for chemical substances carried by ships. GESAMP reports and studies No 64, No 463/03, 137 p. IMO, London

Guerbet M, Jouany JM (2002) Value of the SIRIS method for the classification of a series of 90 chemicals according to risks for the aquatic environment. Environ Impact Assess 22:377-391

Hansen BG, Van Haelst AG, Van Leeuwen K, Van Der Zandt P (1999) Priority setting for existing chemicals: European Union risk ranking method. Environ Toxicol Chem 18(4):772-779

Harold P, Russell D, Louchart P (2011) Risk prioritisation methodology for hazardous \& noxious substances for public health. Atlantic Regions Coastal Pollution Response (ACROPOL), Pembrokeshire County Council, Pembrokeshire

HELCOM (2009) Report on shipping accidents in the Baltic Sea area during 2009. http://www.helcom.fi/ stc/files/shipping/shipping_accidents_2009.pdf. Accessed 21 May 2012

HELCOM (2012) Accidents and response: compilations on ship accidents in the Baltic Sea area. http:// www.helcom.fi/shipping/accidents/en GB/accidents/. Accessed 5 Oct 2012

Holma E, Heikkilä A, Helminen R, Kajander S (2011) Baltic Port List 2011 - Annual cargo statistics of ports in the Baltic Sea Region. Centre for Maritime Studies, University of Turku, Finland

Häkkinen A (Ed.) (2009) Vaarallisten aineiden kuljetus 2007—viisivuotisselvitys (Transport of dangerous goods in 2007-five-year report). Ministry of Transport and Communications 44/2009. 44 p http:// www.lvm.fi/c/document_library/get_file?folderId=339549\&name=DLFE-9535.pdf\&title= Julkaisuja\%2044-2009. Accessed 10 Feb 2012

Häkkinen J, Kiiski A, Malk V, Myyrä M, Penttinen OP (2010) Kemikaalikuljetus-onnettomuuteen varautuminen Kymenlaaksossa, Ympäristöriskien arviointi ja puh-distusmenetelmien valinta (Preparedness for chemical transport accident in Kymenlaakso, Evaluation of environmental risks and suitable remediation methods). Final report of the ChemRisk project. University of Helsinki, Finland

Hänninen S, Rytkönen J (2006) Transportation of liquid bulk chemicals by tankers in the Baltic Sea. VTT Publications, Espoo

IMO (2007) Report of the Marine Environment Protection Committee on its fifty-sixth session. MEPC 56/ 23/Add.1. IMO, London

Jeong SW, An YJ (2012) Construction of a chemical ranking system of soil pollution substances for screening of priority soil contaminants in Korea. Environ Monit Assess 184:2193-2204

Juraske R, Antón A, Castells F, Huijbregts MAJ (2007) PestScreen: a screening approach for scoring and ranking pesticides by their environmental and toxicological concern. Environ Int 33:886-893

Kujala P, Hänninen M, Arola T, Ylitalo J (2009) Analysis of the marine traffic safety in the Gulf of Finland. Reliab Eng Syst Safe 94:1349-1357

Mullai A (2007) A risk analysis framework for maritime transport of packaged dangerous goods - a validating demonstration. Department of Industrial Management and Logistics. Engineering Logistics, Lund University, Sweden

Mullai A, Larsson E (2008) Hazardous material incidents-some key results of a risk analysis. WMU J Marit Aff 7(1):65-108

Nikunen E, Leinonen R (2002) Ympäristölle vaaralliset kemikaalit—riskinarviointi ja luokitus (Environmentally hazardous chemicals_risk assessment and classification). Chemical Industry Federation of Finland. Hakapaino Oy, Helsinki 
PortNet system (2012) PortNet system's hazardous cargo declarations and cargo manifests. Finnish Transport Agency, Helsinki

Posti A, Häkkinen J (2012) Survey of transportation of liquid bulk chemicals in the Baltic Sea. Centre for Maritime Studies, University of Turku, Finland

Singh K, Ihlenfeld C, Oates C, Plant J, Voulvoulis N (2011) Developing a screening method for the evaluation of environmental and human health risks of synthetic chemicals in the mining industry. Int. J. Mineral Process 101:1-20

Swanson MB, Davis GA, Kincaid LE et al (1997) A screening method for ranking and scoring chemicals by potential human health and environmental impacts. Environ Toxicol Chem 16(2):372-383

Suominen M, Suhonen M (2007) Dangerous goods related incidents and accidents in the Baltic Sea region, vol 7:2007. DaGoB, Turku

Särkijärvi J, Stenberg J, Tuomarmäki H, Saurama A (2009) Baltic Port list 2008. Annual cargo statistics of ports in the Baltic Sea Region. Centre for Maritime Studies, University of Turku, Finland

Särkijärvi J, Terhokoski P, Saurama A, Helminen R, Holma E (2010) Baltic Port list 2009. Market review of cargo development in the Baltic Sea ports. Centre for Maritime Studies, University of Turku, Finland 